\title{
PISTOKKAIDEN JUURRUTUSAJAN JA JUURISTON PITUUDEN VAIKUTUS KRYSANTEEMIN KEHITYKSEEN
}

\author{
ERKKI KAUKOVIRTA \\ Helsingin yliopiston puutarhatieteen laitos, Viik, Helsinki
}

Saapunut 12. 2. 1966

Lyhytpäiväkrysanteemin viljelyssä on pistokastaimien kasvukunnolla ratkaiseva vaikutus satotulokseen. Pistokkaan laatu riippuu useista tekijöistä, kuten emotaimien elinvoimaisuudesta, juurrutusajan kasvuolosuhteista ja juuriston voimakkuudesta. Uusimmat viljelyoppaat (2, 7 ja 9$)$ pitävät pistokkaiden kasvukunnon kannalta tärkeänä lisäksi sitä, että pistokkaat juurrutuksen aikana säilyttävät kasvuvoimansa. Yleisesti tiedetään, että kasvuvoima riippuu mm. kasvin iästä, tässä tapauksessa pistokkaan kasvukunto pistokkaan iästä.

Pistokkaan ikä johtuu ensinnäkin emotaimesta pistokkaaksi leikattavan kasvin osan iästä ja toiseksi pistokastaimen kasvattamiseen kuluvasta ajasta.

Pistokasverson iän vaikutusta krysanteemin kehitykseen tutkivat Furuta ja Kiplinger (4). He mittasivat tämän tekijän vaikutusta vihkokrysanteemien (kukkavarressa useampi kuin yksi kukinto) kukintaan kukintosarjan laadun perusteella ja havaitsivat,että kahdeksan viikon ikäisistä versoista otetuista pistokkaista kehittyi sopusuhtaisempi kukintosarja kuin nuoremmista versoista otetuista pistokkaista. He havaitsivat myös, että latvaversoista kasvatettujen yksilöiden kukinta oli laadullisesti parempaa kuin sivuversoista otetuista pistokkaista kasvatettujen taimien.

Pistokkaiden kasvattamiseen kuluva aika riippuu ratkaisevasti siitä, istutetaanko juurtuneet taimet suoraan penkkeihin vai kasvatetaanko niitä ensin toisaalla. Allerton (1), Bull (2) ja Kaukovirta (6) ovat tutkineet tämän seikan vaikutusta krysanteemin kehitykseen ja todenneet, että suoraan kasvupaikalleen istutetut taimet kehittyvät nopeammin kuin koulitut. Näitä tuloksia tukevat myös Quarrell'in ja Cooke'n (8) saamat tulokset, sillä he havaitsivat, että penkeissä juurrutetut krysanteemit kehittyivät paremmin kuin ruukuissa, laatikoissa tai multapaakuissa juurrutetut krysanteemit.

Pistokkaiden juurrutusaika niin ikään kuuluu osatekijänä pistokkaan ikään. Juurrutusajan vaikutukseen krysanteemien kehityksessä ei kuitenkaan edellä selostetuissa tutkimuksissa ole kiinnitetty huomiota. Tästä syystä suoritettiin Puutarhatieteen laitoksella aikaisempiin krysanteemin monistuskokeisiin (6) liittyvänä tutkimus, jossa selvitettiin mainitun tekijän vaikutusta krysanteemin kehitykseen. 


\section{Menetelmä}

Tutkimukset suoritettiin Viikissä Puutarhatieteen laitoksen käytössä olleissa kasvihuoneissa v. 1962. Pistokkaiden juurrutus suunniteltiin siten, että toinen erä pistokkaista sai juurtua 10 vuorokautta ja toinen erä 16 vuorokautta. Juurrutus tapahtui hiekka-alustalla sumulaitteiden alla, joiden toimintaa säädettiin käsin tarpeen mukaan. Pistokkaaksi leikattiin emotaimien pääversoista n. $3 \mathrm{~cm}: n$ pituinen latva, ja niiden pistämisessä seurattiin Kains'in ja McQuesten'in (5) ohjeita. Juurrutushuoneessa oli päivälämpötila keskimäärin $18^{\circ} \mathrm{C}\left(15-21^{\circ} \mathrm{C}\right)$ ja yölämpötila $5^{\circ} \mathrm{C}$ :ta alhaisempi, $11-15^{\circ} \mathrm{C}$. Koelajike oli Paradise.

Juurtuneet pistokkaat luokiteltiin kolmeen ryhmään juuriston pituuden mukaan seuraavasti:
A. juurten pituus enintään $3.5 \mathrm{~cm}$
B. " $" 3.5-5.0 \mathrm{~cm}$
C. " " yli $5.0 \mathrm{~cm}$

Juuriston pituus mitattiin pistokkaan tyvestä juurten kärkeen, kuitenkin siten, ettei $1-3$ yksittäistä ja selvästi muita juuria lyhempää tai pitempää juurta otettu huomioon.

Edellisen luokittelun mukaisesti lajitellut taimet istutettiin kasvupaikalleen, turvealustalle 11. 6. Kerranteita oli 4 ja kuhunkin kerranteeseen istutettiin 7 tainta. Lyhytpäiväkäsittely aloitettiin istutusta seuranneena päivänä. Viljelytoimenpiteet, kuten kastelu ja lannoitus, suoritettiin samoin kuin kaupallisessa krysanteemin viljelyssä on tapana (9).

Kokeen järjestelyssä sovellettiin osaruutujen menetelmää. Tulosten tilastollinen tarkastelu suoritettiin Cochran'in ja Cox'in (3) mukaan.

Kasvuajan lämpöolosuhteet kasvihuoneessa ilmenevät kuvasta 1 .

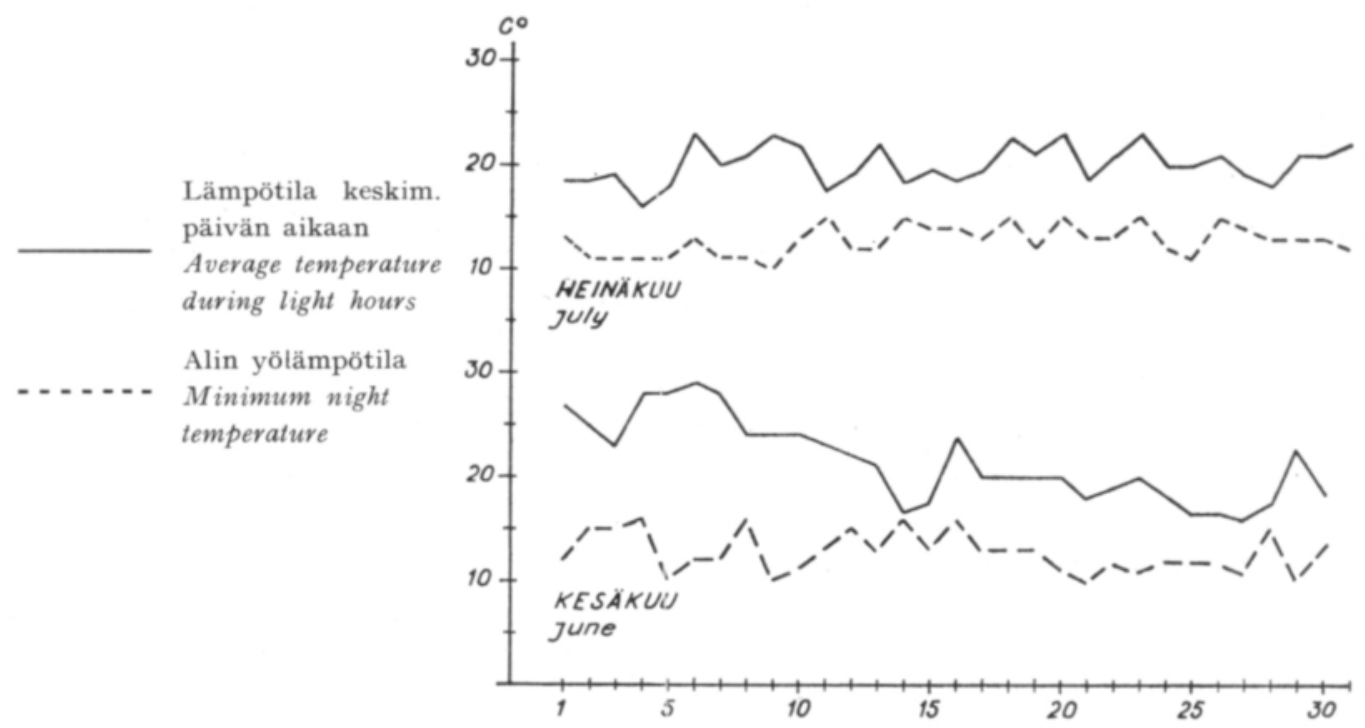

Kuva 1. Kasvatusajan lämpötilat kasvihuoneessa

Fig 1. Temperatures during cultivation in the greenhouse 


\section{Kokeen tulokset}

Taimien kasvua seurattiin suorittamalla kerran viikossa kasvumittaukset ensimmäisen kuukauden aikana istutuksesta lukien. Taulukossa 1 esitetään taimien viikoittainen lisäkasvu kolmen ensimmäisen viikon ajalta.

Taulukko 1. Viikoittainen lisäkasvu istutuksen jälkeen.

Table 1. Rate of growth during the first weeks after planting.

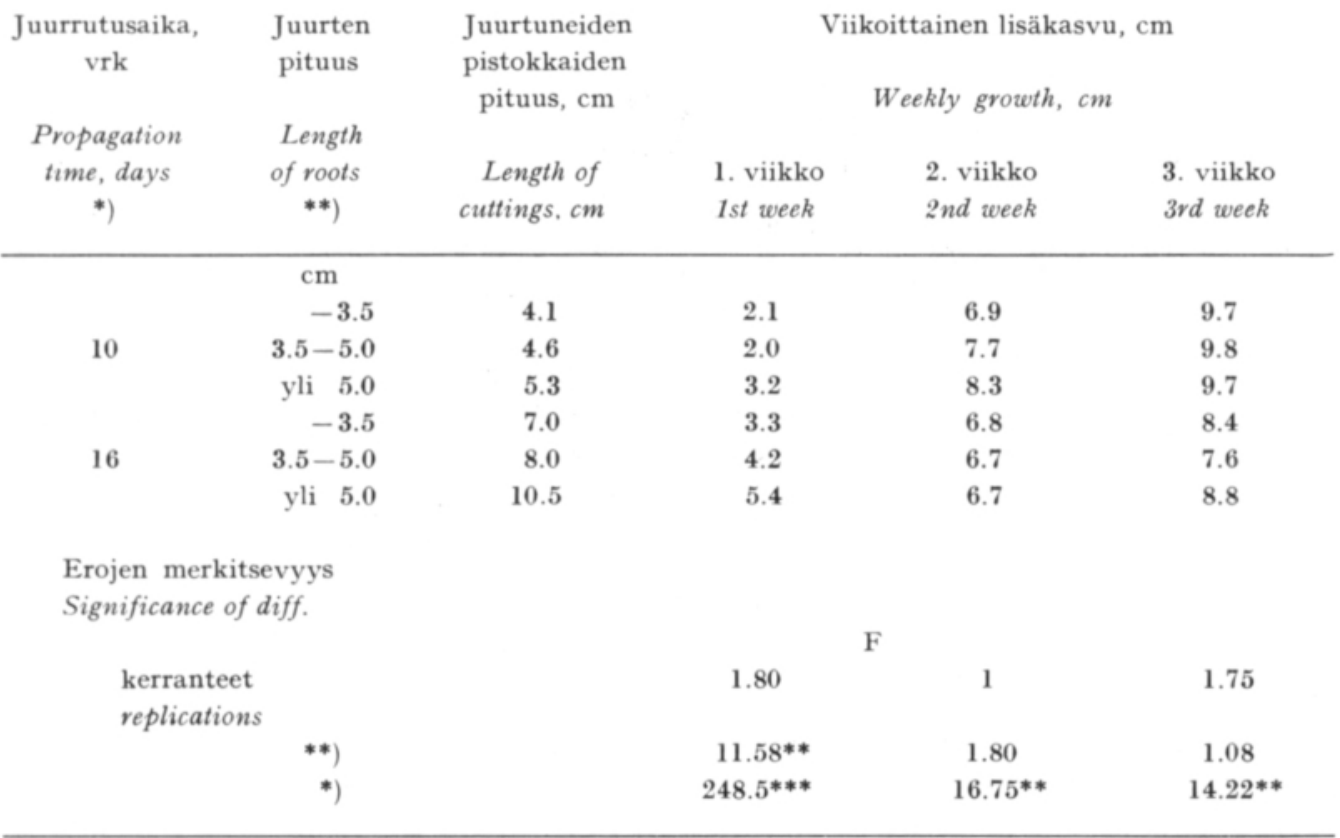

Mittaustulokset osoittavat, että ensimmäisen viikon aikana taimien pituuskasvu oli voimakkaampaa 16 vuorokautta juurtuneissa taimissa kuin 10 vuorokautta juurtuneissa. Toisen ja kolmannen viikon kohdalla tilanne oli muuttunut päinvastaiseksi ja ero oli merkitsevä, kuten taulukossa 1 esitetyt F-arvot osoittavat. Tilanne säilyi samanlaisena kokeen loppuun saakka, kuten taulukossa 2 esitettyjen tulosten perusteella voidaan todeta. Ensimmäisen viikon aikana oli juuriston pituusluokkien välillä verson kasvussa merkitseviä eroja, mutta myöhemmin nämä erot eivät enää ole merkitseviä, kuten ilmenee taulukosta 1 .

Taulukossa 1 esitettyjen tulosten perusteella laskettiin taimien suhteellinen lisäkasvu, mikä esitetään kuvassa 2 . Suhteellinen lisäkasvu määrättiin ottamalla lähtöpituudeksi pistokkaan koko kunkin viikon alussa ja laskemalla kyseisen viikon aikana tapahtunut lisäkasvu yhtä lähtöpituuden senttimetriä kohti. Piirroksesta havaitaan, että kasvuaktiivisuus oli yleensä suurempi 10 vuorokautta juurtuneissa taimissa kuin 16 vuorokautta juurtuneissa. Erityisesti tämä ero on selvä toisen viikon kohdalla kaikkien juurten pituusluokkien osalta $\left(\mathrm{F}=42.04^{* * *}\right)$. Myös kolmannen viikon kasvuaktiivisuus oli 10 vuorokautta juurtuneissa pistokkaissa merkitsevästi parempi kuin 16 vuorokautta juurtuneissa $\left(\mathrm{F}=51.41^{* * *}\right)$. 


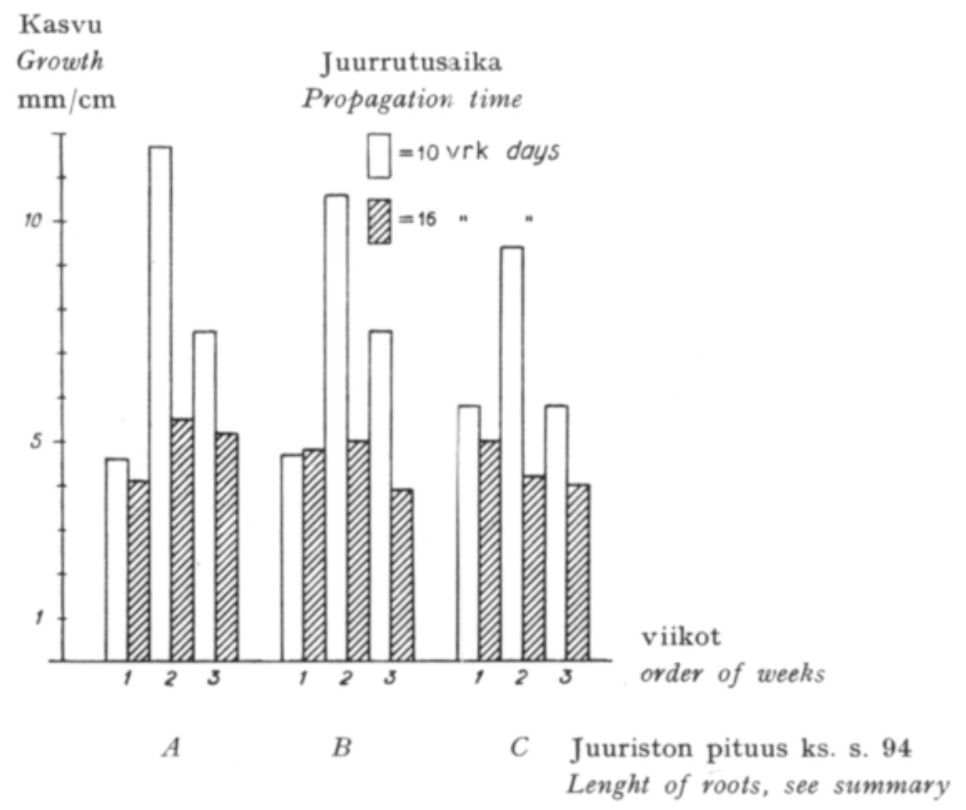

Kuva 2. Verson suhteellinen lisäkasvu

Fig 2. Relative growth rate of stem

Suhteellisen lisäkasvun määrään oli juurten pituusluokilla merkitsevä vaikutus vielä toisen ja kolmannen viikon kohdalla; vastaavat $\mathrm{F}$-arvot olivat $10.78^{* *}$ ja $10.47^{* *}$. Kuvassa 2 pylväsryhmien korkeudesta havaitaan, että suhteellinen lisäkasvu heikkeni juuriston pituuden lisääntyessä.

Taulukko 2. Kukkavarsien pituus ja paino kokeen lopussa.

Table 2. Length and weight of flower stalks at the end of experiment.

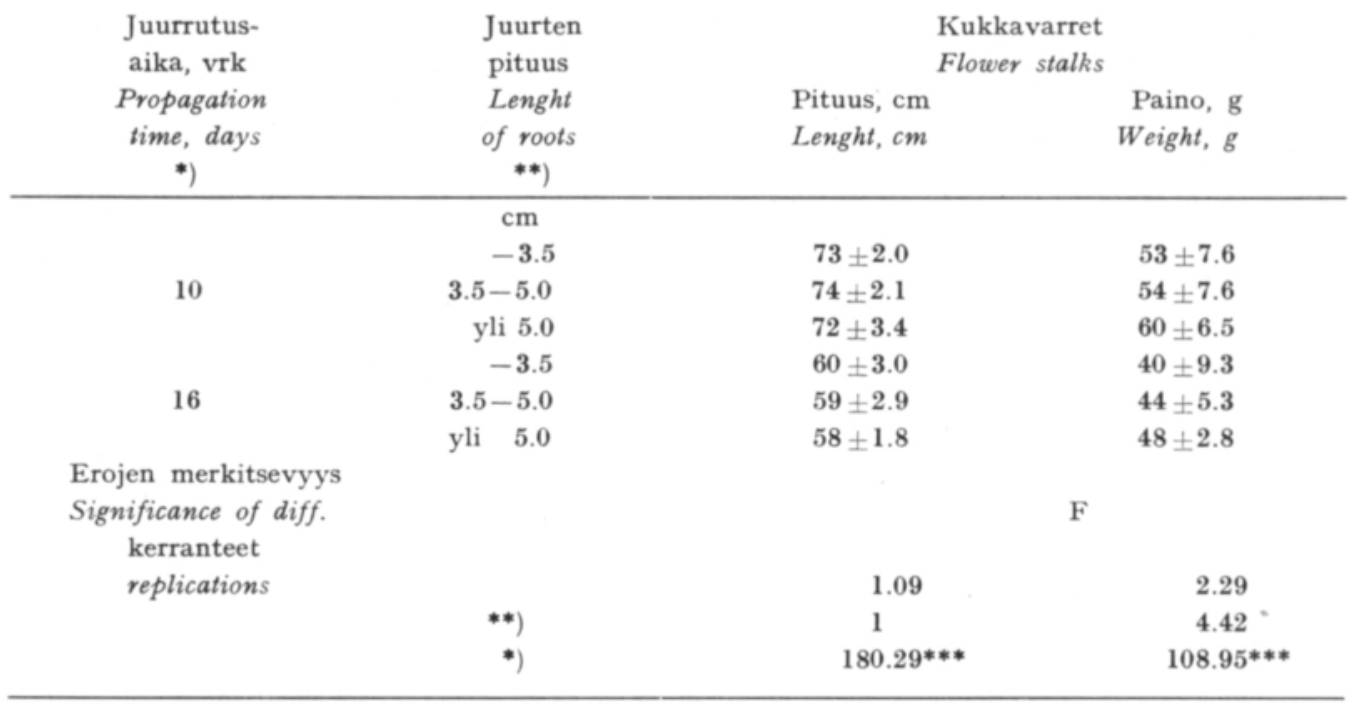


Taulukossa 2 esitetään kukkavarsien pituus ja paino kokeen päättyessä. Tulokset osoittavat, että 10 vuorokautta juurtuneiden pistokkaiden kehittämät kukkavarret olivat merkitsevästi pitempiä kuin 16 vuorokautta juurtuneiden. Lisäksi tuloksista havaitaan, että keskimääräinen verson paino lisääntyi juuriston pituuden kasvaessa, mutta nämä erot eivät ole tilastollisesti merkitseviä, mikä johtuu varsin suuresta hajonnasta.

Kukintojen lukumäärä, ensimmäisen kukinnan läpimitta sekä kukinnan alkamisajat esitetään taulukossa 3 . Kuvassa 3 esitetään varsien jakautuminen kukintojen määrän mukaan.

Taulukko 3. Kukintojen lukumäärä ja koko.

Table 3. Number and size of flowers.

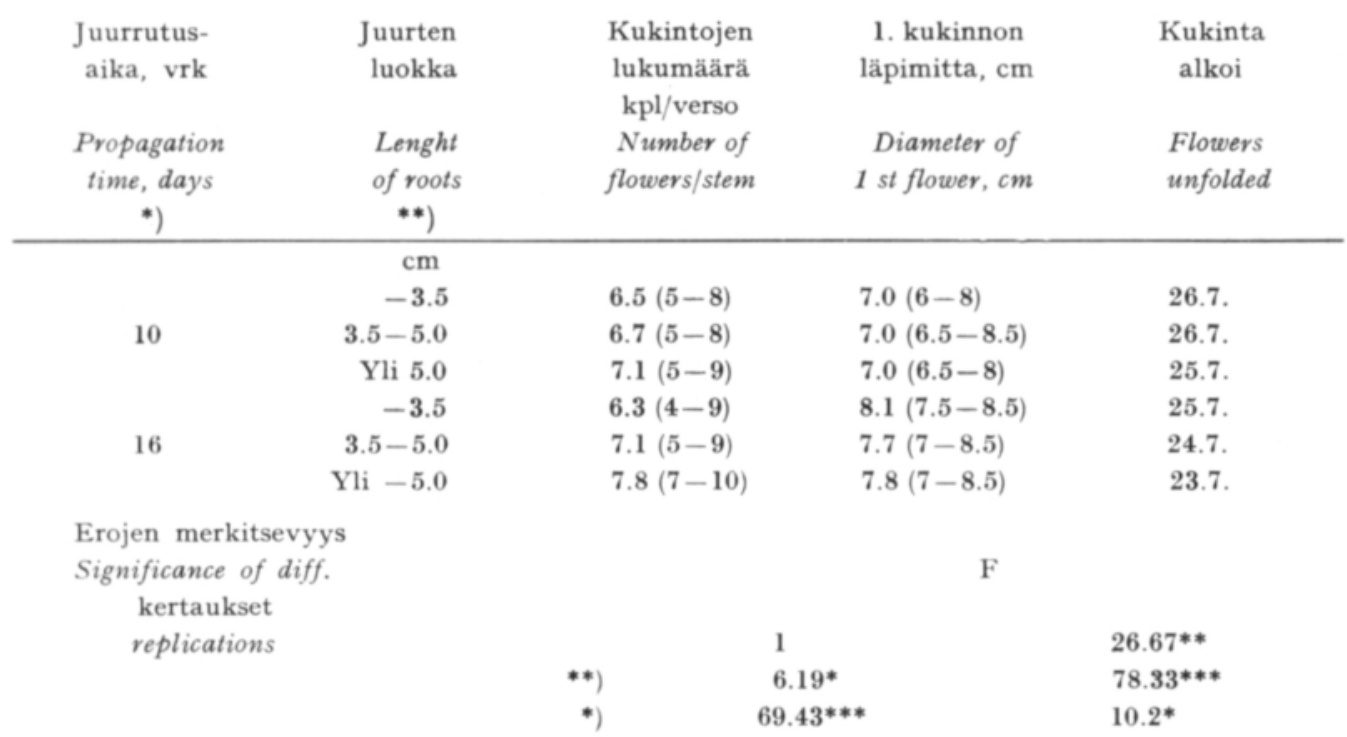

Kukintojen keskimääräinen lukumäärä oli merkitsevästi suurempi 16 vuorokautta juurtuneista kuin 10 vuorokautta juurtuneista taimista kehittyneissä versoissa. Samoin juuriston pituus vaikutti kukintojen määrään siten, että ne taimet, joiden juuret olivat pisimmät, kehittivät useampia kukintoja kuin lyhyempijuuriset taimet.

Kukinnon koko määritettiin ensimmäisen kukinnon läpimittana. Kukinnon koon erot ovat samansuuntaiset kuin kukintojen määrän, mutta edelliset eivät ole yhtä luotettavia kuin jälkimmäiset, sillä erot kerranteiden välillä ovat merkitseviä. Kuitenkin voitiin todeta, että 16 vuorokautta juurtuneista taimista saatiin suurempikukkaisia varsia kuin 10 vuorokautta juurtuneista (kuva 3).

Kukinnan alkamisajaksi merkittiin se päivä, jolloin ensimmäisen kukinnon väri tuli näkyviin. Pitemmän juurtumisajan saaneet taimet alkoivat kukkia jonkin verran aikaisemmin kuin 10 vuorokautta juurtuneet taimet. Tosin erot vastaavien juuriston pituusluokkien välillä olivat vain $1-2$ vuorokautta ja sama ero oli havaittavissa myös kerranteiden välillä. 

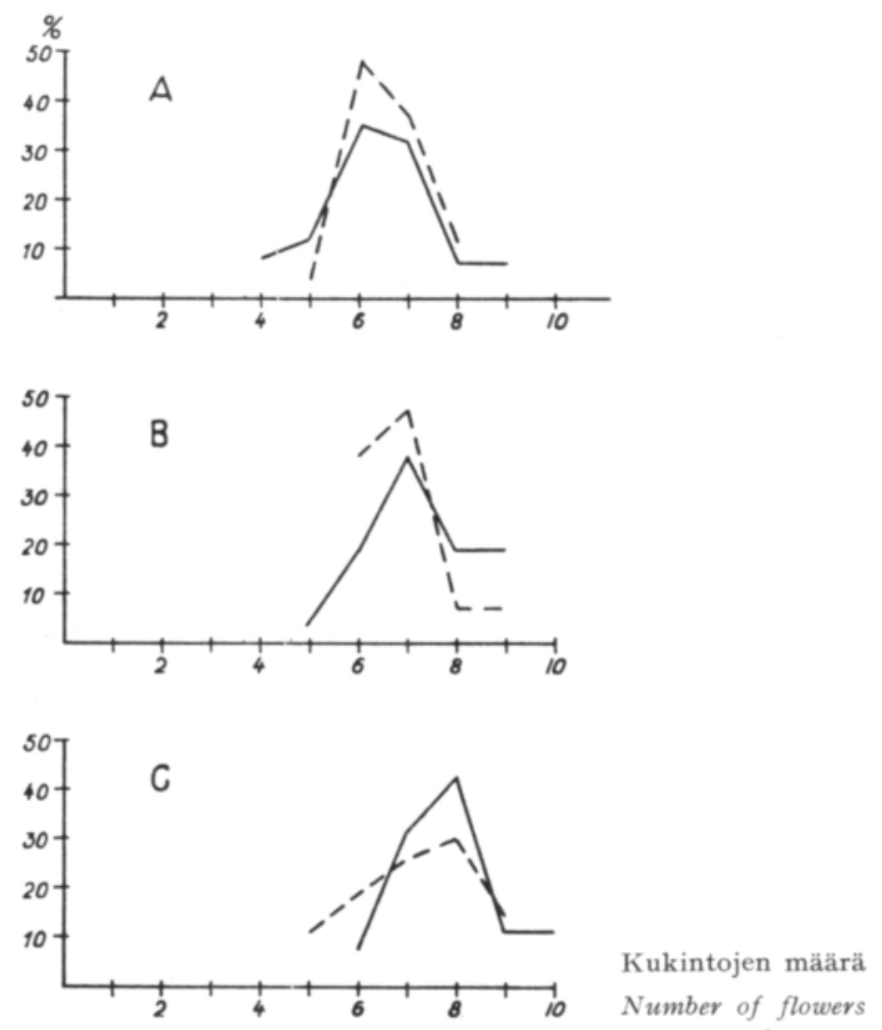

Juurrutusaika

Propagation time

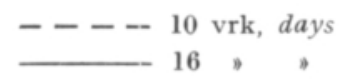

\begin{tabular}{l|l} 
A & ks. s. 94 \\
B & \\
C & see summary
\end{tabular}

Kuva 3. Kukkavarsien jakautuminen kukintojen määrän mukaan

Fig 3. Distribution of stems by the number of flowers

\section{Tulosten tarkastelu}

Juurrutusajan vaikutus kasvuun. Yleisesti krysanteemin pistokkaiden juurruttamiseen lasketaan kuluvan $2-3$ viikkoa. Puutarhatieteen laitoksen aikaisemmin suorittamissa kokeissa oli kuitenkin juurtumisen todettu tapahtuvan jo 11 vuorokaudessa $100-\%$ :sesti hiekka-alustalla. Tästä syystä kokeeseen valittiin tavallista käytäntöä lyhyemmät juurrutusajat.

Juurrutusajalla oli suoritetussa kokeessa selvä vaikutus Paradise-koelajikkeen myöhempään kehitykseen. Viikoittainen verson lisäkasvu oli 10 vuorokautta juurtuneissa taimissa toisesta istutuksen jälkeisestä viikosta alkaen suurempi kuin 16 vuorokautta juurtuneissa taimissa (vrt. taulukko 1). Suhteellinen lisäkasvu oli lyhyemmän ajan juurtuneissa alusta alkaen voimakkaampaa kuin 16 vuorokautta juurtuneissa (kuva 2). Nyt voidaan olettaa, että erot lisäkasvussa ensimmäisten 
viikkojen kohdalta olivat johtuneet siitä, että 16 vuorokauden taimet suurempina kooltaan (taulukko 1) olisivat kärsineet istutuksesta enemmän kuin pienemmät 10 vuorokauden taimet. Tulosten perusteella voidaan kuitenkin päätellä, ettei asia ollut näin, sillä ensimmäisen viikon aikana oli 16 vuorokauden taimissa verson lisäkasvu suurempi kuin lyhyemmän ajan juurtuneissa taimissa. Kun otetaan lisäksi huomioon juurrutusajan vaikutus kukkavarsien pituuteen ja painoon kokeen lopussa (taulukko 2), voidaan pitää ilmeisenä, että taimien kasvukyky heikkeni juurrutusajan lisääntyessä. Tältä osin kokeen tulokset täydentävät ja vahvistavat aikaisemmista krysanteemin taimikasvatuskokeista saatuja tuloksia (6).

Ju uriston pitu den vaikutus kas vu n. Juuriston pituuden vaikutus verson suoranaiseen lisäkasvuun ei ollut suoritetussa kokeessa merkitsevä (taulukko 2). Sen sijaan suhteellisessa lisäkasvussa näkyi juuriston pituuden vaikutus selvästi (kuva 2). Juuriston pituuden lisääntyessä heikkeni verson suhteellinen lisäkasvu. Tämä tulos on yhdenmukainen sen yleisen käsityksen kanssa, että lyhyt ja tuuhea juuristo on edullisin, ja myös niiden tulosten kanssa, jotka Puutarhatieteen laitoksen kokeissa on aikaisemmin saatu (6). Selostetun kokeen perusteella ei kuitenkaan voida tehdä tästä asiasta kiistatonta johtopäätöstä, koska versojen painon kohdalla (taulukko 2) tämä suhde on edellisen kanssa vastakkainen, vaikkakaan ei merkitsevästi.

V a i k u t u s k u k in t a a n. Juurrutusaika vaikutti kukintaan päinvastaisella tavalla kuin verson kasvuun. Taimet, jotka olivat juurtuneet 16 vuorokautta, kehittivät enemmän ja suurempia kukintoja kuin 10 vuorokautta juurtuneet taimet. Lisäksi edellisten kukinta alkoi jonkin verran aikaisemmin kuin jälkimmäisten (taulukko 3 ja kuva 3 ).

Niin ikään juuriston pituus vaikutti kukintaan päinvastaisella tavalla kuin verson kehitykseen. Pitempijuuriset taimet kehittivät enemmän kukkia kuin lyhyempijuuriset (taulukko 3).

Kukinnan osalta selostetun kokeen tulokset poikkeavat niistä, joita Puutarhatieteen laitoksella aikaisemmin suoritetuista kokeista on saatu (6). Tämä ristitiitaisuus johtuikin todennäköisesti siitä, että nyt selostetussa kokeessa aloitettiin lyhytpäiväkäsittely välittömästi taimien kasvupaikalleen istutuksen jälkeen. On ilmeistä, että lyhyemmän ajan juurtuneet taimet eivät olleet riittävästi kehittyneitä lyhytpäiväkäsittelyn alkaessa vastaanottaakseen kukintaärsytyksen. Yleisestihän katsotaan, että taimet tarvitsevat parin viikon kasvuajan istutuksen jälkeen, ennen kuin lyhytpäiväkäsittely voidaan aloittaa.

\section{Yhteenveto}

Pistokkaiden juurrutusajan ja juuriston pituuden vaikutusta tutkittiin kokeessa, joka oli suunniteltu täydentämään aikaisemmin suoritettuja krysanteemin juurrutus- ja taimikasvatuskokeita (6).

Pistokkaiden juurrutusajan piteneminen heikensi selvästi krysanteemin (Paradise) kasvukykyä. Verson lisäkasvu oli merkitsevästi suurempi 10 vuorokautta juurtuneissa taimissa kuin 16 vuorokautta juurtuneissa (taulukot 1 ja 2).

Juuriston pituudella ei ollut merkitsevää vaikutusta suoranaiseen verson 
lisäkasvuun, mutta sen sijaan suhteellinen lisäkasvu heikkeni juuriston pituuden kasvaessa (kuva 2).

Kukintojen lukumäärä varressa ja ensimmäisen kukinnan läpimitta oli suurempi 16 vuorokautta juurtuneissa taimissa kuin 10 vuorokautta juurtuneissa (taulukko 3 ja kuva 3). Tämä ero aiheutui todennäköisesti siitä, että lyhytpäiväkäsittely aloitettiin liian aikaisin.

\section{K I R J A L L I S U U T T A}

(1) Allerton, F. W. 1960. Direct-planted chrysanthemums. Comm. Gr. 3350: 705-707.

(2) Bull, J. 1955. The Bull mum guide. 89 p. Chicago.

(3) Cochran, W. G. \& Cox, G. M. 1962. Experimental designs. 595 p. New York.

(4) Furuta, T. \& Kiplinger, D. C. 1952. Chronological age of cuttings, a factor influencing the spray formation of pompon chrysanthemums, Proc. Amer. Soc. Hort. Sci. 66: 383-385.

(5) Kains, M. G. \& McQuesten, L. M. 1948. Propagation of plants. 639 p. New York.

(6) Kaukovirta, E. 1962. Lyhytpäiväkrysanteemin pistokasmonistus- ja taimikasvatuskokeista. Maatal. tiet. aikak. 34: 197-209.

(7) Post, K. 1949. Florist crop production and marketing. 891 p. New York.

(8) Quarrell, C. P. \& CoOKE, D. 1957. Effect of propagation treatments on cropping of chrysanthemums. Exp. Hort. 1:5-7.

(9) Searle, S. A. \& Machin, B. J. 1957. Chrysanthemum the year round. 273. p. London.

\section{S U M M A R Y : \\ EFFECT OF PROPAGATION TIME AND LENGTH OF ROOT SYSTEM ON GROWTH OF CHRYSANTHEMUMS}

ERKKI KAUKOVIRTA

Department of Horticulture, University of Helsinki, Viik, Helsinki

An experiment was carried out to study the effect of propagation time and length of root system on the development of chrysanthemum, variety 'Paradise'. Two propagation times were tested; 10 days and 16 days. Rooted cuttings were graded into three length groups according to the length of the root system. The length groups were as follows:

$$
\begin{aligned}
& \mathrm{A} \text { - length of root system less than } 3.5 \mathrm{~cm} \\
& \mathrm{~B}-, \quad, \quad \\
& \mathrm{C}-
\end{aligned}
$$

In this experiment the propagation time had a significant effect on the development of chrysanthemum, variety 'Paradise'. The weekly growth of plants of the 10-day propagation period was greater than that of plants of the 16-day propagation time. Also the final length and weight of the flower stalks was greater on the former than in the latter (Tables 1 and 2).

The length of the root system did not affect the actual growth rate of the plants significantly. However, the relative growth rate decreased significantly when the length of the root system increased (Fig. 2).

The number of flowers per stem and the diameter of the first flower were greater on the plants of the 16-day propagation period than on plants with a 10-day propagation time (Table 3 and Fig 3). This effect, however, might be due to too early a short day treatment so that the younger plants were not in a condition to react to flower stimulus as favourably as the plants in the 16-day propagation treatment. 